\title{
We leave a year behind, and we start a new one
}

\author{
Ildefonso Rodríguez-Leyva* \\ Department of Neurology, Faculty of Medicine, Hospital Central Dr. Ignacio Morones Prieto, Universidad Autónoma de San Luis Potosí, SLP, Mexico
}

It is recognized that the country to the north of ours is the result of migration. It seems to be the conjunction of multiple cultures and dreams of people who came searching for opportunities. The desire of those dreamers to make a better society resulted in changes in infrastructure, education, science, and culture that made this nation a robust community.

Immigration continues to be a frequent phenomenon, especially that which originates from places where poverty, insecurity, war, and ignorance prevails, and which lands in places where opportunities for wealth, security, peace, and education can offer better prospects for the quality of life of a human being and their family. In the middle of the last century, Mexican immigration to the United States of America was accepted and promoted by both countries. At that time, half a million individuals arrived to work temporarily and $10 \%(50,000)$ of them remained permanently in the US. Unfortunately, this process has suffered ups and downs that in the last decade have led to xenophobia, segregation, and rejection being promoted in our northern neighbour, provoking a persecutory attitude especially towards undocumented people who stay illegally, considering them people as "offenders" if not "criminals".

Despite this, immigration continues to exist, and with the lack of opportunities, education and economic downturn, it has grown in recent years. As a result, our country is not only the origin of many immigrants, but it is now a passage for multiple caravans that must face a significant number of obstacles and even risk their own lives in the search to reach the so-called "American dream".
Thousands of people are waiting at the Mexican border for an opportunity that will allow them to enter the United States of America. Furthermore, they are in help centres that have emerged from the same society to support these people who left everything to reach a better future for themselves and their offspring. All of them face the health issues that are to be expected in a community that unfortunately does not have a social security system providing them with medical attention, acute, and prophylactic pharmacological therapeutic management, and much less hospital care should they need it. Neurologists' daily cases, such as epilepsy, migraine, and cerebral-vascular disease are only a part of these health issues. As neurologists, we should ideally handle those issues in this population with warmth and high-quality work, which is also exposed to significant stress due to the conditions we face.

Unfortunately, societies insist on remedies instead of solutions. We want to clean the wound instead of avoiding the cause. Promoting education, justice, and culture in countries where immigration originates could be a better remedy than suffering the consequences of a phenomenon that is unfair to those performing it, and evil to those promoting it.

As a neurological guild, there is little we can do to solve such a complex but, at the same time, unfair issue, which we face as a society. Although it was once a phenomenon to be supported and encouraged, perhaps what we should offer now in the fight against poverty, insecurity, and injustice is the promotion of education, job opportunities and personal and
Available online: 03-01-2022

Date of reception: 01-11-2021

Date of acceptance: 12-11-2021

10.24875/RMN.M21000085
Rev Mex Neuroci. 2022;23(1):1-2

www.revmexneurociencia.com (http://creativecommons.org/licenses/by-nc-nd/4.0/). 
community development. Not "giving away the corn cob, but, rather, teaching people how to sow.

Since at the end of the day every act we perform has repercussions on society, let us try to cooperate with it by educating our patients, their families, and friends as we are privileged enough to have received an education and having the resources for advocating for health. Let us inculcate in our children the respect for immigrants, who are not worth less than a common individual just because they have less. If we can help only one of them, let us share what we have. Although their situation will not change, we may give them the strength to continue their search for the dream they are trying to achieve.

A new year begins with unique purposes, new hopes, and the knowledge that our passage through this one will be transitory. Therefore, we hope that a fair world, a more educated country, a happy family, and multiple blessings will come to the life of each one of us and our readers, as well as for the immigrants in, and from our country, in this 2022.

Sincerely yours, Ildefonso Rodríguez-Leyva Editor in Chief 